\title{
Paroxismos e ambivalências, sociotecnias
}

\author{
Paroxysms and ambivalences, sociotechnics
}

\author{
Caco Xavier \\ Assessor da Vice-Presidência de \\ Ensino, Informação e Comunicação da Fundação Oswaldo Cruz \\ caco@fiocruz.br
}

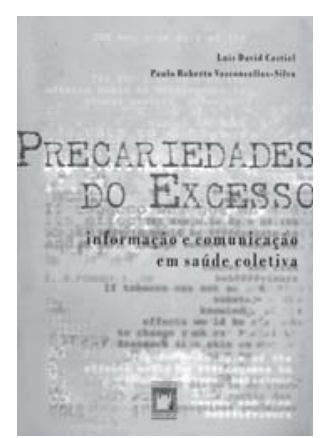

Castiel, Luis David;

Vasconcellos-Silva, Paulo Roberto.

Precariedades do excesso: informação e comunicação em saúde coletiva. Rio de Janeiro: Ed. Fiocruz, 2006. 168p.
$\mathrm{P}$ ara Luis Castiel e Paulo Roberto Vasconcellos-Silva, autores do livro em questão, o "paroxismo mediante paradoxismo" (auto)designado no título deve "portar com eficácia a identidade do texto" (p.16, 19). Missão cumprida. E mais: o texto é claríssimo, sobretudo porque os autores assumem plenamente suas intenções, mesmo nos instantes em que a atitude diante do objeto principal - as questões da saúde coletiva atravessadas pelas dimensões dos recursos e objetos comunicacionais e pelas Tecnologias de Informação e Comunicação (TICs), notadamente a internet - apresenta-se honestamente ambivalente. 'Ambivalência', no contexto desse trabalho, tem a força e a coragem de um conceito estruturante no tocante a tais objetos. No texto, toda ambigüidade deve ser, e assim é, afastada por princípio, porque nublaria o pensamento, enquanto que a ambivalência, ao contrário, o ilumina e enriquece de sentidos.

Uma resenha descritiva de Precariedades do excesso parece tarefa bastante facilitada, já que os autores explicitam quase didaticamente, de quando em quando, os objetivos do trabalho, e as palavras 'crítica', 'ambivalência' e 'tecnologia' aparecem continuamente: “O livro coloca seu foco crítico em distintos aspectos das TICs - destacando o uso da internet - que vêm marcando acentuadamente o campo sanitário contemporâneo" (p.20); "Em síntese, trata-se de explorar criticamente o fato ambivalente de que, ao lado das indiscutíveis vantagens tecnológicas, reside uma considerável perda das medidas" (p.16); “Este livro, entre outros temas colaterais, trata de compulsões coletivas e de outros efeitos adversos criados pelo avassalador carrossel de produção, transmissão e consumo de signos como bens acumuláveis" (p.145); "Critica-se aqui a idéia de conhecimentos trazidos à luz por vozes hegemônicas ... criticam-se as verdades industrializadas" (p.145).

O objeto é complexo e ambivalente, a intenção primeira é a crítica, de um lado quase kantiana, no sentido de estabelecer os limites de nossas possibilidades de conhecimento acerca de um assunto, digamos, de conformação ainda tão imprecisa, e de outro muito próxima do sentido hipocrático de postar-se diante de um evento-limite de grande significação aguardando seu desfecho. Uma resenha descritiva, portanto, porque facilitada, ao invés de aguçar a curiosidade intelectual do leitor, corre o risco de aparentemente a satisfazer, levando-o a perder aquilo que parece ser o próprio espírito do livro: instaurar um diálogo interno e/ou uma ação comunicativa. Em respeito aos autores e, principalmente, aos potenciais leitores de Precariedades do excesso, tal resenha está, assim, descartada. 
Schopenhauer diz, em famoso ensaio nos Parerga und Paralipomena, e não exatamente com essas palavras, que ler é emudecer a mente e deixarse guiar pela mão de outros. O texto de Castiel e Vasconcellos-Silva, ao contrário, obriga-nos a largar as mãos dos 'outros' (no caso, eles mesmos) e abrir a mente ao diálogo. Seja 'trialogando' com os autores no interior de seus próprios diálogos - explicitados ou não em suas páginas, nas notas de rodapé e na extensa bibliografia -, seja, principalmente, induzindo-nos a inserir 'nossos' autores e referências e idéias 'favoritas' em seus argumentos, polemizando com eles, altercando-nos, por vezes discutindo ferozmente. Opto por evidenciar, nesta resenha, apenas um (ou uns) dos vários diálogos possíveis que se dão ou podem se dar durante e mesmo após a leitura do livro. Na verdade, e nesse sentido, esta é uma resenha excessivamente precária.

Nossa primeira impressão é um paralelismo quase poético entre a contemporaneidade exposta no livro e aquelas outras: de Gutenberg e sua galáxia, diálogo trazido à baila pelo hoje em dia tão injustamente esquecido Marshall McLuhan, e da revolução atômica abordada no magistral pronunciamento de Martin Heidegger, em comemoração ao centenário da morte do compositor Conradin Kreutzer. As palavras de Heidegger, proferidas há quase sessenta anos, bem que poderiam estar impressas na apresentação desse livro: "Tem lugar uma revolução em todas as representações cardeais", "e o homem se traslada assim a outra realidade"; "Nasce daí uma posição totalmente nova do homem no mundo e a respeito do mundo" (Heidegger, Serenidad, 1994). O ponto do pensador alemão - e também do profeta da aldeia global - é o mesmo dos autores de Precariedades: como se portar, que atitude tomar diante de uma revolução de tal monta, caracterizada, naqueles e também em nossos tempos por "excessos de possibilidades, incertezas e ansiedades" (p.120)?

Patinando entre dois 'efes', fetiche e fobia - polarização que costuma acompanhar os estudos sobre a técnica -, viviam naqueles tempos e vivemos nós. Encantamento ou afastamento, abraço ou recusa, divide-se o mundo em apocalípticos e integrados, tecnófilos e tecnófobos, com a bem-vinda opção, lá e aqui, da tecnoambivalência. A palavra escolhida por Heidegger para experenciar a atitude de um simultâneo e crítico 'sim' e 'não' diante da técnica aplica-se, igualmente, ao espírito do trabalho e da reflexão de Castiel e Vasconcellos-Silva: Gelassenheit, serenidade. É um livro sereno, nesse sentido, e ainda assim - talvez por isso mesmo - inquietante.

Mas, susto, poderia ser diferente. O prefácio de Javier Sanz Valero, apesar de levantar alguns pontos interessantes, desperta dois grandes incômodos. O primeiro ao asseverar, com ares de preocupação, que "não convém passar ao largo de que a técnica é apenas um meio, não um fim em si mesma" (p.8), e o segundo ao expressar surpresa em relação ao animal ser humano capaz de criar a internet, mas que, mesmo responsável pelos 'progressos da ciência', "continua acreditando em mitos, em objetos invisíveis ou em entes de existência incomprovável" (p.11). Se a segunda afirmação é uma ironia em relação aos 'novos mitos' da chamada 'sociedade do conhecimento', o efeito, ainda assim, é ambíguo. Afortunadamente, nem um nem outro apare- 
cem com tintas tão fortes no texto de Castiel e Vasconcellos-Silva. O livro, embora permaneça na chave do primeiro pensamento como pano de fundo, é capaz de abrir algumas janelas. Chegaremos lá.

Dividir o mundo entre seres reais e seres imaginários, ciência e mito, objetos visíveis e invisíveis, no entanto, soa no mínimo como uma perigosa improcedência em relação às TICs, pautadas pela dissolução do real, pela virtualização do mundo e pela invisibilidade constitutiva de atores e processos. Tão 'mitológica' quanto uma biblioteca babélica medieval pode me parecer uma interface cujo algoritmo (que palavras mitológicas!) me coloca à disposição, a um toque de dedos, o conteúdo das maiores bibliotecas e enciclopédias do mundo, com corredores e labirintos ainda mais intrincados.

O livro, no entanto, não assume essa direção entendida no prefácio; ao contrário, investe na crítica do excesso precário, como uma contemporânea hybris informacional. Ao questionar tal hybris em relação aos princípios que regem, ou devem reger, a saúde coletiva, fornece não só elementos para compreendê-la como ainda para confrontá-la e, se preciso, reagir a ela. Permanecendo nos gregos, o livro é lido como pharmakón contra pharmakón. Edgar Morin, em Cabeça bem-feita (2003), repete T.S. Eliot e pergunta-se "Onde está o conhecimento que perdemos na informação? E onde está a sabedoria que perdemos no conhecimento?". Castiel e Vasconcellos-Silva aprofundam e complexificam essa pergunta, trazendo-a para o âmbito estrito da saúde e das TICs em relação à saúde. "Em síntese, trata-se de explorar criticamente o fato ambivalente de que, ao lado das indiscutíveis vantagens tecnológicas, reside uma considerável perda das medidas" (p.16).

Realizei uma leitura não-linear desse trabalho. Índice, primeiro; a seguir folheei todo o livro retendo os (muito elucidativos) títulos de capítulos e entretítulos, prenhes de intenções; depois, prefácio, apresentação e o capítulo 1, "Interface internet/s@aúde", capítulo-medula a reunir em si e 'amarrar' os demais; depois, salto direto para a conclusão e, só então, leitura dos quatro capítulos mais estanques e temáticos. Ao final, fica a sugestão de uma releitura do capítulo 1.

A estrutura do livro segue um padrão bastante didático ao público não familiarizado com as TICs ou a comunicação e informação em saúde. Uma Apresentação sucinta diz a que vem o trabalho, justificando sua abordagem, e o primeiro capítulo enfoca as TICs, o excesso hybrido por elas produzido e facilitado e sua relação com a suposta autonomia para a saúde, baseada nas quase-recentes - e reduzidas - teorias de que mais informação é sempre igual a melhores decisões. (E temos em hybrido um trocadilho bem-vindo, mesclando a hybris grega, aqui em forma de desmedida informacional, e o hibridismo constitutivo das mídias contemporâneas, reunindo humanos e não-humanos em redes sociotécnicas e dessegmentando os sentidos.)

Os capítulos 2, 3, 4 e 5 tratam de temas específicos que orbitam as TICs: a explosão de impressos destinados para orientação de pacientes dos grandes hospitais; a epidemiologia da desinformação (ou infodemiologia) como nova educação sanitária do século XXI; a medicina baseada em evidências, que depende grandemente da informática e da internet; e as chamadas informação e comunicação de risco, com 
exemplos da biotecnologia. A conclusão do trabalho remete à "necessidade de uma ética global voltada para problemas de saúde pública", em que um certo compromisso é proposto e requerido (p.24). Como provocação aos autores, fica a sentida lacuna de um ensaio sobre a mídia que mais impacta o imaginário da população brasileira e sua relação com o fog conceitual e semântico acerca dos diversos sentidos da 'saúde', sua cientifização e mercantilização descarada: a TV aberta.

Feita essa 'cobrança' necessária e urgente - já que infelizmente não existem muitas análises com esse recorte específico e tão fundamental -, organizo então o diálogo com os autores em torno de apenas duas questões, centrais e mutuamente implicadas: a questão da mídia/meio e a idéia necessariamente dela decorrente, que reconfigura a noção de pessoa e mesmo de sociedade em razão de como nos postamos frente às TICs. A nova hybris seria um terceiro ponto, mas não creio que seja necessário. Traduzida por 'desmedida' pelos principais comentadores da filosofia e poesia gregas, a hybris (pós)moderna é portadora de um paradoxo contemporâneo: “Os excessos de mensagens neutralizariam nossa capacidade de processá-las cognitiva, crítica e emocionalmente", dizem Castiel e Vasconcellos-Silva no espírito da formulação de Edgar Morin (p.46), e tal crítica - que no livro se desdobra em muitos exemplos, dados e argumentos - parece adequada e suficiente.

Se Valero, em seu Prefácio, não quer esquecer que a técnica é "apenas um meio e não um fim em si", Castiel e Vasconcellos-Silva entendem as TICs como um meio, sim, mas como tal em relação a um fim, a promoção da saúde (p.25), e é nessa direção/relação que baseiam todo o texto e todas as idéias, com raros momentos de exceção. É nesse ponto que, penso, encontra-se a principal lacuna do livro. Ou melhor, é aí que os autores impedem-se de avançar ainda um pouco mais, ao não considerar uma importante alternativa de abordagem. Nesse ponto, e para ilustrar meus argumentos e sugestões, lanço mão de três convidados: Bruno Latour, com Jamais fomos modernos (1994) e, principalmente, o recente Reassembling the social (2005); Alfred Gell e seu Art and agency; e Marshall McLuhan, com o famoso Understand media, mas especialmente com o quase desconhecido tratado sobre a escrita fonética, a prensa e suas implicações, chamado A galáxia de Gutenberg. Cada um desses autores e trabalhos, a seu modo, alargam e reconfiguram a idéia de 'meio', 'mediação', 'ação' e 'agência', justo aquilo que parece fazer falta ao trabalho de Castiel e Vasconcellos-Silva.

Uma das preocupações básicas de Latour, que figura incidentalmente na bibliografia do livro, ao descrever as inquietações de sua teoria-ator-rede (ANT, a partir das iniciais em inglês), é justamente o papel dos atores não-humanos numa rede social. Para ele (e também para Gell e McLuhan, como veremos a seguir), toda análise capaz de atribuir a não-humanos um tipo de agência que seja mais larga do que a tradicional causalidade natural e mais eficiente do que uma 'agência simbólica', contribui para enriquecer a compreensão dos fenômenos complexos. Por agência, Latour não entende necessariamente 'ação', dizendo mesmo que trazer objetos (e aqui estamos sempre falando de tecnologias de informação e comunicação, internet, computadores, sites, sistemas e objetos tais) para o curso normal das ações pode parecer 
inócuo. No entanto, ele assegura que a pergunta mais relevante a se fazer, a respeito de qualquer agente (humano ou não-humano) é: ele faz diferença no curso das ações de outros agentes ou não? Há alguma forma de se detectar essa diferença? (Latour, 2005, p.71). Assim, um 'ator', na expressão hifenizada 'ator-rede', não é apenas a fonte de uma ação, mas "o alvo móvel de um vasto elenco de entidades que se encaminham para ela" (p.46).

Desse modo, por definição, a ação é sempre deslocada, emprestada, distribuída, sugerida, influenciada, dominada, traída, traduzida, 'mediada'. Um objeto (ou uma técnica, ou um sistema, ou qualquer outro elemento que podemos denominar 'meio') não é jamais 'mera ferramenta', porque é sempre capaz de modificar os objetivos que temos em mente, já que nos permite produzir certos efeitos que não seriam possíveis de se obter sem tal objeto ou mesmo por meio de algum outro. São, portanto, atores (ou actantes) em rede de agências (ou ações) distribuídas. Se entendemos que quem 'faz' é sempre o elemento humano (falamos de intenção e significação), não podemos descuidar do fato de que muitos outros elementos (humanos e não-humanos) 'fazem-fazer', do mesmo modo que uma faca 'corta' e uma pedra 'faz' o carro desviarse. A linguagem não eclipsa o elemento humano à toa. "Frita, ovo! Pinga, pia!" E tudo obedecia à mãe do poeta Paulo Leminsky, em conhecido poemito-agência. (E McLuhan [1972, p.85] dizia que são os artistas aqueles mais capazes de perceber a verdadeira natureza do presente.) Para Latour, em sua proposta de rede sociotécnica de elementos humanos e não-humanos, não há ferramentas, nem meios, apenas 'mediadores'. E os mediadores, em sua terminologia, são sempre criativos e portadores de agência, do mesmo modo que um cigarro, para os franceses, é capaz de 'faire-fumer'.

Para Alfred Gell, pesquisador preocupado com o modo pelo qual a antropologia sempre lidou com objetos 'artísticos' de constituição diferente dos tradicionais objetos ocidentais, aquilo que ele chama de agência social não pode ser definido em termos de atributos biológicos básicos (que distingue entre 'objeto inanimado' e 'pessoa encarnada'), porque é sempre 'relacional'. Para ele, isso não tem a ver com o que a 'coisa' ou a 'pessoa' de fato 'é' em si mesma, mas sim de que maneira e onde ela se insere em uma rede de relações sociais (Gell, Art and agency, 1998, p.123). O que se requer, então, é que tais 'agentes sociais' sejam, nesse sentido, pessoas-agentes nessas relações, ainda que não sejam biologicamente 'pessoas humanas'.

Por fim, relembrando Marshall McLuhan, vemos que suas proposições, nos anos 60 e no prenúncio das tecnologias eletrônicas, longe de serem 'datadas' ou 'ultrapassadas', são, ao contrário, atualíssimas e úteis. A Galáxia de Gutenberg, seu primeiro livro, de 1962, ao traçar um panorama das implicações da escrita, sobretudo da escrita fonética (alfabeto) e da prensa na história humana, alude de maneira extraordinariamente lúcida ao porvir-presente, prefigurando nossa revolução eletrônica-cibernética pós-moderna por aquela, mecânica e iluminista.

"Meus consumidores, não são eles meus produtores?", pergunta-se McLuhan pela pena de James Joyce em Finnegan's Wake (McLuhan, A Galáxia de Gutenberg, 1972, p.370) antevendo a descentralização e frag- 
mentação da produção de informações a partir das redes eletrônicas. E é pela pena de outro autor, William Blake, que McLuhan ilustra o embrião de sua mais famosa assertiva ("o meio é a mensagem"), ao registrar o verso "Se os órgãos da Percepção mudam, os Objetos da Percepção parecem mudar" (McLuhan, 1972, p.353). Referindo-se aqui ao alfabeto e à prensa, McLuhan diz que é aí que se instaura uma certa tecnologia do individualismo em detrimento do coletivo. "Se os homens decidirem modificar essa tecnologia visual para uma tecnologia elétrica, o individualismo também será modificado" (Mcluhan, 1972, p.220). O erro, segundo ele, é que os historiadores e estudiosos tinham a tendência de isolar os eventos tecnológicos, à maneira como os físicos clássicos lidavam com os eventos naturais. "Agora, na idade da eletricidade, a própria instantaneidade da coexistência entre nossos instrumentos tecnológicos deu lugar a uma crise sem precedente na história humana. As extensões de nossas faculdades e sentidos passaram a constituir um campo único de experiência que exige a se fazer coletivamente consciente" (McLuhan, 1972, p.22).

O ponto a destacar é que aquilo que McLuhan entende por 'meio' (media) cabe perfeitamente na idéia de inclusão de atores e agências não-humanas numa rede sociotécnica. Veja a frase premonitória, com ênfase minha: "O meio é a mensagem, porque é o meio que configura a forma e a proporção das ações e associações humanas" (McLuhan, Understand media, 1964, p.23). Isto é, aquilo que ele chama 'meio' é ator inserido numa rede de relações sociais, e possui agências em tal rede. A investigação minuciosa dessas agências não deve ser desprezada na consideração das TICs, já que é mesmo essencial a elas.

Insisto no fato de que a leitura atenta desses (pelo menos) três autores é capaz de expandir nossa compreensão das TICs, incluindo-as e a todos os seus aparatos como portadores de agências de diversos quilates e qualidades, de modo que possamos analisá-los em suas naturezas complexas e híbridas, responsáveis por grandes cadeias de ações que implicam diretamente numa reconfiguração do que entendemos por 'pessoa' e mesmo por 'sociedade'. E aqui entramos no segundo bloco de questões, de certo modo contempladas pelos autores de Precariedades (p.56, 58), mas talvez não suficientemente explicitadas.

Quase sempre somos tentados a ver pessoas e configurações sociais implicadas em novas formas de organização segundo as mesmas lentes de uma organização anterior, que nos seja mais familiar. Lidar com as pessoas e atores (ou uma certa 'sociedade') envolvidas com as TICs segundo a conformação de um 'sujeito cartesiano' ou de uma sociedade hegeliana, pode levar a grandes equívocos. Quem é essa 'pessoa' (ou paciente, ou consumidor de saúde, ou usuário) que está em rede e na rede? Quem é este que se automedica pela rede, que realiza consultas, que busca evidências, que consome e coleta informações como um novo nômade de sentidos? (McLuhan, 1972). Se Balandier o denomina homo cathodicus, mediado por teclas, há sempre a possibilidade de se estender bastante essa mediação e chamá-lo homo semioticus (mediado por signos de toda espécie) ou, inspirado na bios midiatikós de Muniz Sodré (Reinventando a cultura: a comunicação e seus produtos, 2001), de homo mediaticus, mediado... pelas próprias mídias! Infinitas possibilidades de 
ser e apresentar-se no mundo (igualmente novo e diferente) e também de relacionar-se com ele, desde a pessoa distribuída de Gell (1998), ao sujeito-cebola de Roy Wagner (The invention of culture, 1981), passando pela pessoa fractal de Marilyn Strathern (The gender of the gift: problems with women and problems with society in Melanesia, 1988).

Creio que o importante a saber e reconhecer é que novos ambientes geram novas (conformações e tipos de) pessoas, bem como novas espécies de 'colas' para o que quer que se chame 'social' (Latour, 2005). Importante ainda é saber e reconhecer, humildemente, que definitivamente não sabemos, a priori, que pessoas e que tipos de relações são essas. Isto é, é preciso descobri-las a partir de, e em, suas relações com as TICs, do mesmo modo como é preciso analisar as TICs a partir dessas 'novas' pessoas e relações. Em resumo, não perder o sujeito, nem o objeto, muito menos o trajeto. Ao contrário, acatar a sugestão dos autores e permanecer atentos, capazes de "enfrentar os efeitos, na saúde, dos paroxismos tecnológicos" (p.150). Lembrando subitamente do prefácio e dos entes mitológicos e de existência não comprovada, talvez não creiamos em tais paroxismos, pero que los hay, los hay!

\section{REFERÊNCIAS BIBLIOGRÁFICAS}

Gell, Alfred
1998
Heidegger, Martin
1994
Latour, Bruno
2005
Latour, Bruno
1994
McLuhan, Marshall
1972
McLuhan, Marshall
1964
Morin, Edgar
2003
Schopenhauer, Arthur
1988
Sodré, Muniz.
2001
Strathern, Marilyn
1988
Wagner, Roy
1981

Art and agency.

New York: Oxford University Press.

Serenidad.

Barcelona: Edicionaes del Serbal.

Reassembling the social.

New York: Oxford University Press.

Jamais fomos modernos.

Rio de Janeiro: Ed. 34.

A galáxia de Gutenberg.

São Paulo: Cia. Ed. Nacional.

Understand media.

New York: McGraw-Hill Book Company.

A cabeça bem-feita: repensar a reforma, reformar o pensamento.

Rio de Janeiro: Bertrand Brasil.

Parerga und paralipomena.

Züric: Haffmans.

Reinventando a cultura: a comunicação e seus produtos.

Petrópolis: Vozes.

The gender of the gift: problems with women and problems with society in Melanesia. Berkeley: University of California Press.

The invention of culture. Chicago:

The University of Chicago Press.

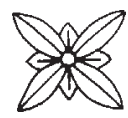

